\title{
O SABER ARGUMENTATIVO NA FORMAÇÃO DOCENTE DURANTE A PANDEMIA DE COVID-19
}

\author{
ARGUMENTATIVE KNOWLEDGE IN TEACHING TRAINING DURING THE COVID-19 \\ PANDEMIC
}

CONOCIMIENTO ARGUMENTATIVO EN LA FORMACIÓN DE PROFESORES DURANTE LA PANDEMIA DEL COVID-19

Eliana Cristina Rosa E-mail: eliana.rosa@uftm.edu.br

Mayron Engel Rosa Santos

RESUMO E-mail: mayrondiscens@gmail.com

Este ensaio tem como objetivo descrever e refletir sobre como a não exposição de argumentos e pontos de vista interfere na formação dos professores. O tema foi levantado pelos autores, em 2020, ano em que a pandemia gerou a necessidade da continuidade dos estudos de forma virtual. Neste processo de reflexão sobre as formações iniciais dos professores e conflitos advindos da migração das aulas presenciais para o ambiente virtual, foram percebidas quantas camadas/interferências existem e que explicam a não argumentação dos alunos em aula, desde possíveis processos de formação com pouco estímulo à argumentação até questões sociais e emocionais, como o fato de não terem equipamentos adequados; vergonha da sua condição doméstica; a falta de pacote de internet necessário para o acesso; dificuldade na gestão do tempo e ansiedade.

PALAVRAS-CHAVE: Formação docente. Saber argumentativo. Pandemia Covid-19.

\section{ABSTRACT}

This reflection in the essay format aims to describe how the non-exposure of arguments and points of view interfere in the training of teachers. The theme was raised by the authors in 2020, the year in which the pandemic generated the need for continuity of studies in a virtual way. In this process of reflection on the initial training of teachers and conflicts arising from the migration of classroom classes to a virtual environment, it was noticed how many layers exist in the non-argumentation of students in class, from possible training processes with little incentive to argumentation, to social issues. and emotional, such as the fact that they do not have adequate equipment, ashamed of their domestic condition; the lack of internet package necessary for access; and difficulty in managing time and anxiety.

KEYWORDS: Teacher training. Argumentative knowledge. Covid-19 pandemic.

\section{RESUMEN}

Esta reflexión en formato ensayo tiene como objetivo describir cómo la no exposición de argumentos y puntos de vista interfiere en la formación de los docentes. El tema fue planteado por los autores en 2020, año en que la pandemia generó la necesidad de continuidad de estudios en una forma virtual. En este proceso de reflexión sobre la formación inicial de los docentes y los conflictos derivados de la migración de las clases presenciales al entorno virtual, se notó cuántos estratos hay en la no argumentación de los estudiantes en clase, a partir de posibles procesos de formación con poco estímulo a la argumentación, a cuestiones sociales y emocionales, como no tener el equipo adecuado, avergonzarse de su condición doméstica; la falta del paquete de Internet necesario para el acceso; y dificultad en la gestión del tiempo y ansiedad.

PALABRAS-CLAVE: Formación docente. Conozca argumentativo. Covid-19 pandemico. 


\section{INTRODUÇÃO}

A proposta deste ensaio é refletir como a não exposição de argumentos e pontos de vista interfere na formação dos professores. Estas constatações foram construídas após o estudo da disciplina "Formação de Educadores e Contemporaneidade: Políticas, Concepções e Práticas" do Programa de Pós-Graduação de uma universidade pública, em 2020. Este estudo tornou-se plausível, pois, com o advento da pandemia, gerou-se a necessidade da oferta do ensino remoto/virtual pela universidade e demais órgãos educacionais.

Neste processo de reflexão, cabe situá-los a respeito do público e dos eventos analisados: aulas de mestrado em Educação, com um público (alunos) em sua maioria advindo dos cursos de licenciatura. Nesse universo, foi observado que, no decorrer do estudo da disciplina, houve uma quantidade mínima de manifestações argumentativas (durante as aulas virtuais) sobre os temas levantados em aula, e com expressiva dificuldade dos alunos diante da migração das aulas para o formato virtual, de um curso que era essencialmente presencial.

Assim, este ensaio nasce com o intuito de trazer reflexão, curiosidade, indagação a respeito da realidade a todos imposta, pois é fruto da "curiosidade como inquietação indagadora, como inclinação ao desvelamento de algo" (FREIRE, 2001), menos tese e mais diálogo. Porém, pretende preservar o rigor acadêmico, com o propósito de refletir e descrever como o debate de ideias pode fortalecer a construção de saberes para a docência, trazendo também neste contexto como se deram os conflitos advindos da migração das aulas presenciais para o ambiente virtual durante a pandemia da Covid-19. Assim, então, foi definido que essas discussões se dariam por meio do gênero ensaio.

A escolha pelo gênero ensaio foi estritamente pessoal e acadêmica, com vistas à aplicação dos conhecimentos adquiridos na disciplina "Formação de Professores". Portanto, foi feita a opção por uma obra de reflexão sobre o tema com viés pessoal, como afirma Hillebrand (apud JANZ, 2016, p. 56): “O ensaio não pretende encerrar uma questão, quer abrir os espíritos; deseja transformar a difícil matéria de conhecimento em vida fluida; não pretende lecionar, mas educar; não visa à transmissão de conhecimentos, mas incentivar a reflexão".

Pois bem, a disciplina ora citada propiciou a oportunidade de aprofundar os conhecimentos fundamentais sobre: Formação de Educadores; Formação de Professores no Contexto Pluriétnico; e Avaliação de Programas Educacionais. As aulas ocorreram no período 
de 08/09/2020 a 15/12/2020, no formato virtual da disciplina, como descrito, em virtude da situação pandêmica causada pelo novo Coronavírus.

É fato que nossa geração nunca viveu uma situação tão devastadora, num mundo dito globalizado e desenvolvido, que trouxesse tantas modificações no cotidiano, como mudanças drásticas nas estruturas organizacionais das empresas, instituições educacionais com alterações na oferta de ensino — do presencial para o remoto/virtual—, e na vida de toda a população, com visíveis crises políticas e econômicas severas. "A pandemia da Covid-19 colocou luz sobre desigualdades sociais que já existiam, talvez esquecidas ou não vistas". (MATTA, et al., 2021, p. 35).

Enfatizamos então o contexto conturbado no universo educacional ora mencionado que serviu/serve de pano de fundo a este estudo. Para as reflexões e análises aqui colocadas, analisamos quatro aulas disponibilizadas no drive da turma, passíveis de análise por qualquer componente do grupo de acesso, além da participação nessas aulas como aluno. Embasamos, portanto, nesse material nossas observações e percepções.

Aos analisarmos o material, surgiram algumas inquietações: A formação acadêmica anterior ao Programa interfere no processo autônomo de exposição de ideias? O ambiente virtual e a situação pandêmica influenciaram no desempenho dos alunos?

Desta forma a questão da Formação Docente não se desenvolve apenas com um método, um caminho específico adequado, porque o ato educativo está ligado ao fenômeno social, e este está sempre em mudança. Diante desse pressuposto, devemos propor e rever ações fundamentais para a prática docente, sendo a reflexão e o debate também meios para o conhecimento e o aprendizado. Freire $(1985$, p. 61) descreve que "quanto mais for levado a refletir sobre sua situacionalidade, sobre seu enraizamento espaço-temporal, mais emergirá dela conscientemente carregado de compromisso com sua realidade da qual [...] não deve ser simples espectador".

\section{REFERENCIAL TEÓRICO}

Estudos descrevem que um dos pontos que mais dificultam a qualidade da profissionalidade é a herança tecnicista: abordando os conhecimentos e práticas de forma racionalista, contribuindo para formação de professores pouco reflexivos, que temem o debate de ideias. 
No contexto brasileiro, inúmeras são as críticas aos cursos de formação inicial de professores. Entre elas, destacam-se a dicotomia das aulas práticas e teóricas, a falta de uma interação harmoniosa entre os conhecimentos específicos da área com a parte pedagógica e a falta de espaço para os licenciandos refletirem sobre os processos de ensino e de aprendizagem. (MALDANER, 2000; BROIETTI; BARRETO, 2009, apud PENTEADO, 2010).

Diante desse paradigma tecnicista, o espaço para argumentação é reduzido e o professor em formação se torna mero reprodutor de conteúdos e métodos didáticos, minimizando a capacidade de produzir conhecimento, sendo que a habilidade de argumentação contribui de forma significativa na consolidação e validação do conhecimento. Como afirma Leitão (2007, p. 454),

A argumentação - forma de discurso caracterizada pelas operações discursivas de justificar pontos de vista, considerar e responder a perspectivas contrárias - gera nos sujeitos a possibilidade de refletirem sobre os fundamentos e limites do seu conhecimento, ao mesmo tempo em que os engaja em um processo de revisão de suas próprias perspectivas.

Desta forma quando confrontamos ideias de forma respeitosa, estamos buscando possibilidades, ampliando os horizontes, na construção de resolução para problemas complexos, mobilizando saberes anteriores e validando os novos, capacitando o profissional ao processo contínuo de reflexão, exigência comum à profissionalidade da docência (ASSMANN, 2012).

Portanto, a argumentação é um processo reflexivo contínuo, que busca soluções para problemas advindos da prática docente, que serão ou não expostos mediante o espaço disponível para a fala. $\mathrm{O}$ ambiente educacional deve proporcionar o diálogo e com ele meios para que a exposição de ideias reflexivas e argumentativas torne-se efetiva, sendo assim um dos principais protagonistas nesse meio e que torna isso viável é o professor que está em contato direto com o aluno. É interessante compreendermos também que cabe aos futuros docentes entender e exigir esse espaço para argumentação.

Quando vivenciamos espaços democráticos de fala, oportunizamos a dimensão do entendimento do outro. Quando abandonamos o paradigma tecnicista, abrimos espaço para a validação do conhecimento através do debate de ideias, ou seja, menos formatos pedagógicos que buscam respostas e mais propostas que criam perguntas, como afirma Assmann (2012, p. $33)$.

É preciso substituir a pedagogia das certezas e dos saberes pré-fixados por uma pedagogia da pergunta, do melhoramento das perguntas e do "acessamento" de informações. Em suma, por uma pedagogia da 
complexidade, que saiba trabalhar com conceitos transversais, abertos para a surpresa e o imprevisto. [grifos no original]

Neste primeiro ponto, é relevante discutir a identidade profissional do professor, embasado em Gatti (2010, p._1360): é imprescindível que se estabeleça os conhecimentos e ações necessárias para um bom exercício docente, e assim "adentrar a concepção de um profissional que tem condições de confrontar-se com problemas complexos e variados, estando capacitado para construir soluções em sua ação, mobilizando seus recursos cognitivos e afetivos". (GATTI, 2010).

\section{MATERIAIS E MÉTODOS}

Como suporte metodológico foi utilizada a opção por uma obra de reflexão sobre o tema com viés pessoal por meio do gênero ensaio.

As questões trabalhadas foram: A formação acadêmica anterior ao Programa interfere no processo autônomo de exposição de ideias? O ambiente virtual e a situação pandêmica influenciaram no desempenho dos alunos?

\section{ANÁLISE DOS DADOS E RESULTADOS}

Durante as aulas, houve uma média frequente de alunos, considerando o todo de discentes matriculados. Foi verificada uma média expressivamente pequena de participações ativas durante as aulas, sendo que as demais participações foram induzidas pelos professores de forma diretiva através de perguntas realizadas aos alunos. Das participações ativas, houve somente uma pequena parcela: em média, dez por cento da turma se colocou à disposição do debate, ficando claro, portanto, a baixa participação dos estudantes.

E neste viés, segue-se para a segunda questão: $O$ ambiente virtual e a situação pandêmica influenciaram no desempenho dos alunos? Sabemos que muitas foram as intempéries neste percurso, pois no mês de março de 2020, as aulas foram suspensas por quatro meses, e somente no mês de agosto, iniciou-se a discussão sobre o retorno no formato virtual. Sendo democrático o processo; fomos consultados e, através de consenso da maioria, atestaram a necessidade do retorno às aulas, agora de forma remota.

E para entender um pouco mais do processo de volta às aulas e as possíveis influências do formato virtual no aprendizado dos cursistas, foram disponibilizadas para conhecimento duas questões que se mostraram relevantes neste percurso: a falta de condições técnicas para 
assistir às aulas e dificuldades com a gestão do tempo entre estudo e afazeres domésticos, de home office. Cabe ainda lembrar que se trata de curso em universidade pública, com um público diversificado em relação a questões sociais de trabalho e recursos; cada qual com sua similaridade. O fato é que a maioria precisa trabalhar, e o tempo que estão em aulas no mestrado são horas/aulas a menos nos seus honorários do trabalho.

É importante também mencionar que não foi pensada a necessidade de analisar se os discentes teriam condições de voltar às aulas, o que acarretou vários problemas, tais como: inacessibilidade ao conteúdo disponibilizado devido à baixa qualidade do pacote de internet em sua moradia; falta de acessórios adequados para assistir às aulas; falta de espaço adequado.

Além disso, mais algumas situações foram percebidas, como: alunos que assistiam às aulas pelo celular por falta de conexão eficaz com a internet em computadores (pois o celular dispõe de recursos melhores para trabalhar com internet de baixa velocidade), ou pelo fato de em casa haver o compartilhamento de um único computador com outros membros da família; alunos que não conseguiam ouvir a aula por conta do barulho doméstico, e também a ausência de equipamentos adequados, como fone de ouvido e microfone.

Quando olhamos para a relação da gestão do tempo, foi percebida a dificuldade de conciliar as aulas com os cuidados com os filhos que, devido à pandemia, também estavam em casa; isso faz com mais ajuda ou atenção sejam exigidos dos pais/responsáveis. Ademais, identificamos queixas sobre a dificuldade de adaptação ao virtual e às complexas conexões entre os ambientes virtuais, formatos de aulas, trabalhos em grupos e avaliações que foram enfrentados pelos alunos.

Houve episódios em que foram utilizadas plataformas diferentes dentro do Programa, gerando, dessa forma, dificuldades com os ambientes virtuais: a disciplina de "Formação de professores" utilizou a plataforma do Google; e as demais, a do Moodle. O fato é que a oscilação no uso de diferentes plataformas dificultou o acesso às informações ou mesmo aos materiais exigidos em aulas, os locais para postar atividades, as interações com os demais alunos, além de senhas e logins diferentes para cada ambiente, ocasionando um stress geral.

Sendo também observado como obstáculos para o desenvolvimento de relações dialógicas o fato de professores e alunos não se conhecerem de forma presencial $\left(1^{\mathrm{o}} \mathrm{semestre}\right.$ desta turma). Essa situação dificultou o acolhimento e a recepção ao diálogo, fato que poderia ser amenizado se já estivesse havido um contato pessoal entre eles; e assim durante as aulas, 


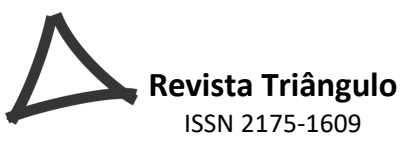

muitos permaneciam com suas câmeras e microfones desligados. Fica a reflexão se seria por vergonha do espaço físico em que se encontravam, ou será que não abriram o áudio por conta do barulho das crianças brincando na casa?!

Neste intento, é fundamental reconhecer o processo de argumentação como poderoso agente de mudança, que possibilita refletir sobre os acontecimentos, ao mesmo tempo que aciona mecanismos de respostas amplificadas, pois, ao considerar e responder a outros pontos de vistas, oportunizamos a revisão de nossas próprias perspectivas.

Diante deste cenário reflexivo e, principalmente, no momento vivenciado com a pandemia estabelecida, é necessário estabelecer caminhos que levem a conhecimentos e ações básicas para o exercício docente. É uma necessidade e um desafio cada vez maior e somente "pensando criticamente a prática de hoje ou de ontem que se pode melhorar a próxima prática”. (FREIRE, 2001, p. 440).

Ademais, a falta de estímulo dos recursos argumentativos ao aluno provoca uma separação, um distanciamento entre aluno-aluno, aluno-professor e aluno-professorinstituição, impossibilitando a mobilização através da busca de soluções que beneficiem o todo. Sendo um papel importante e necessário a busca de uma educação modificadora e estimuladora no presente e futuro aluno-professor, a qual desenvolve e apreende todo esse universo no seu habitat natural de profissão.

\section{CONSIDERAÇÕES FINAIS}

Neste processo de compreender, refletir e descrever, foi percebido quantas podem ser as causas para a não argumentação de alunos em aulas virtuais, desde possíveis processos de formação com pouco estímulo à argumentação, questões sociais, emocionais, ausência de equipamentos adequados, internet insuficiente para o acesso virtual, e/ou a vergonha da sua condição doméstica, bem como a dificuldade na gestão do tempo e a ansiedade estabelecida são questões importantes e que devem ser colocadas na balança pelo docente, pela instituição educacional nos novos tempos.

Assim para construir um futuro mais promissor, com certeza precisamos de reflexão para desenvolver conhecimentos que sejam um elo entre a teoria e a prática. Necessitamos abrir espaços para o diálogo entre as esferas de poder das instituições acadêmicas, para que assim a classe de professores e alunos se unam e dialoguem para o bem comum da profissão e 
do ser humano, não somente em tempos de pandemia, mas com o olhar no futuro que nos espera.

\section{REFERÊNCIAS}

ASSMANN, H. Reencantar a educação: rumo a sociedade aprendente. Petrópolis - RJ: Vozes, 2012.

FREIRE, P. Educação e mudança. Traduzido por Moacir Gadotti e Lilian Lopes Martins. 10 ed. Rio de Janeiro: Paz e Terra, 1985.

FREIRE, P. Pedagogia da Autonomia: saberes necessários à prática educativa. São Paulo: Paz e Terra, 2001.

GATTI, B. A. Formação de professores no Brasil: características e problemas. Educ. Soc. [online]. 2010, vol.31, n.113, p.1355-1379.

JANZ, C. P. Friedrich Nietzsche: uma Biografia. Vol. I, II e III. Petrópolis, RJ: Editora Vozes, 2016.

LEITÃO, S. Argumentação e desenvolvimento do pensamento reflexivo. Psicologia: Reflexão e Crítica, 20 (3), 454-462, 2007.

MATTA, G.C.; REGO, S.; SOUTO, E.P.; SEGATA, J. Os impactos sociais da Covid-19 no Brasil: populações vulnerabilizadas e respostas à pandemia [online]. Rio de Janeiro: Observatório Covid 19. Editora FIOCRUZ, 2021, 221 p. Informação para ação na Covid-19 series. ISBN: 978-65-5708-032-0. <https://doi.org/10.7476/9786557080320>

PENTEADO, H. D. Pesquisa-ensino e formação de professores. In: PENTEADO, H. D., GARRIDO, E. (Org.) Pesquisa-ensino: a comunicação escolar na formação do professor. São Paulo: Paulinas, 2010. 